\title{
Shear Performance of FRCC Beam-Column Joints Using Various Polymer Fibers
}

\author{
Yu Mu, Akira Yasojima and Toshiyuki Kanakubo \\ Department of Engineering Mechanics and Energy, University of Tsukuba, Tsukuba-City, Ibaraki 305-8573, Japan
}

\begin{abstract}
Brittle shear failure should be avoided in beam-column joint of a reinforced concrete (RC) frame during the earthquake. Fiber-reinforced cementitious composite (FRCC) which presents a remarkable deformability especially under tensile and bending load with a large energy absorption capacity is expected to be used in the crucial part of a RC frame. With the development of polymer material, various synthetic fibers have become the best selection to improve concrete capacity and failure resistance without the corrosion of fibers. The objective of this study is to investigate the influence of fiber bridging effect on the shear capacity of FRCC beam-column joint. The main parameter of the test in the present study is the fiber types: aramid, polypropylene (PP) and polyvinyl alcohol (PVA) fiber. To evaluate shear capacity quantitatively, a new calculation method using FRCC tensile characteristics confirmed by the uniaxial tension test is newly proposed. The difference of below $7 \%$ between calculated value and experimental value demonstrates that the calculation method is feasible.
\end{abstract}

Key words: Shear, uniaxial tension test, aramid, PP, PVA.

\section{Introduction}

Beam-column joint is the crucial part of a reinforced concrete (RC) frame, which is to ensure the ductility of the whole structure especially when the frame is subjected to huge earthquake. Under seismic response, major damage should be avoided in the beam-column joint. Even the beam and column step into inelastic state, the joint has to remain the ability to transfer actions. The reasons to avoid large damage in beam-column joint under seismic response are to keep transferring capacity of the gravity load in the panel zone, to accomplish large ductility and energy dissipation by other elements such as beam, and difficulty of repairing the joint after earthquake [1].

Shear failure in the panel zone causes a typical brittle damage in beam-column joint, so its shear capacity should be given gratifyingly. Shear capacity of beam-column joint is mainly supplied by the dimensions of the panel zone and concrete strength. An adequate amount of lateral confining

Corresponding author: $\mathrm{Yu} \mathrm{Mu}, \mathrm{Ph} . \mathrm{D}$. candidate, research fields: concrete structures, fiber-reinforced cementitious composites. reinforcement in the panel zone also provides non-shear failure. In general, however, the dimensions of the panel zone are limited by the dimensions of connecting columns and beams. In addition, increasing confining reinforcements will cause great construction difficulties in reinforcement cage and casting.

Using fiber-reinforced concrete into panel zone of beam-column joint to increase shear capacity is not a new attempt [2-12]. By the introduction of steel fibers in beam-column joints, steel fiber-reinforced concrete (SFRC) is an attractive alternative to inhibit the damage of joint panel and increase maximum load. However, decreased stress caused by steel fiber corrosion $[13,14]$ is a severe problem that has to be faced. With the development of polymer material, various synthetic fibers have become the best selection to improve concrete capacity and failure resistance without the corrosion of fibers $[15,16]$.

A newly cementitious-composite-based material named fiber-reinforced cementitious composite (FRCC) is cement composite with the mixture of short fibers to increase ductility of cement composite. 
Comparing to the conventional concrete, FRCC has a remarkable deformability especially under tensile and bending load with a large energy absorption capacity due to the fiber bridging effect. After first cracking, fiber can transfer tensile force through crack which strongly affects the tensile performance of FRCC [17]. This remarkable bridging capacity makes it an appropriate choice for application in beam-column joint of RC structures to resist inelastic deformation. Until now, FRCCs can be constituted with a category of fibers, such as carbon [18], steel [19] and polymer fibers [20]. Whereas, most research in materials field has been focused on FRCC with a high modulus polyethylene (PE) fiber, and has been conducted by bending and tensile test [21]. Structural performance of beam-column joints using polyvinyl alcohol (PVA) $[22,23]$ and steel fiber [24] in panel zone with a fiber volume fraction of $1 \%$ has been confirmed. Fibers can restrain expansion of crack width, increase shear capacity and improve structural performance rather than the specimen without fiber. The previous research [25] has also revealed that PP-ECC (a sort of polypropylene fiber-reinforced cementitious composite) can serve as transverse reinforcements to carry the applied load.

Precast construction method which is widely used in RC buildings especially in high skyscraper in Japan becomes more and more popular by ensuring better quality, simplified install procedure and shorter duration. Until now, a new precast system which casts the joint panel combining with beam and separating column into two parts has been proposed. Even though the FRCC constructability is tough, by adopting this precast method, FRCCs can be used in practical engineering easily. Therefore, it is a smart way of enabling FRCC to play a better role in a beam-column joint.

In this research, various polymer fibers have been utilized in the FRCCs beam-column joint to increase shear capacity and reduce the damage of the panel zone. Compared with steel fiber, polymer fibers have a better durability in cement matrix. The loading test of FRCCs beam-column joints with a fiber volume fraction of $1 \%$ is conducted to make clear the influence of fiber type on shear capacity of panel zone. Tensile performance of FRCCs characterized from uniaxial tension test is also discussed. A new calculation method for evaluating shear capacity of FRCCs beam-column joint is proposed based on the standard of Architectural Institute of Japan (AIJ) [26].

\section{Outline of Test}

\subsection{Material Properties}

The target compressive strength of the FRCCs was set to $50 \mathrm{MPa}$. As listed in Table 1, water-cement ratio of 0.56 was adopted, which is based on the previous study [17], fiber volume fraction for each specimen was $1 \%$. The mechanical properties of each polymer fiber are shown in Table 2 and Fig. 1. Aramid fiber and PP fiber are fibrillated with a same length of 30 $\mathrm{mm}$, while $12 \mathrm{~mm}$ for PVA fiber. Diameter for aramid, PP and PVA is $0.5 \mathrm{~mm}, 0.7 \mathrm{~mm}$ and $0.1 \mathrm{~mm}$ independently. Aramid fibers having an extraordinary tensile strength of 3,432 $\mathrm{MPa}$ have been used in aircraft, military vehicles, bullet proof vests and many others. The used aramid was stranded from single fibers. Surface roughness embossing has been made on the PP fiber to improve the bond property.

\subsection{Test Specimens}

Two specimens (No. 30 and No. 31) were designed

Table 1 Mixture proportion of FRCC.

\begin{tabular}{lllllll}
\hline \multirow{2}{*}{ Fiber volume fraction (\%) } & \multirow{2}{*}{ Water-binder ratio } & \multirow{2}{*}{ Sand-binder ratio } & \multicolumn{4}{c}{ Unit weight $\left(\mathrm{kg} / \mathrm{m}^{3}\right)$} \\
\cline { 3 - 7 } & & & Water & Cement & Fly ash & Sand \\
\hline 1.0 & 0.39 & 0.50 & 380 & 678 & 291 & 484 \\
\hline
\end{tabular}

Cement is high-early-strength Portland cement; fly ash is Type II of Japanese Industrial Standard (JIS A 6202); sand is size under $0.2 \mathrm{~mm}$; high-range water-reducing admixture is binder $\times 0.6 \%$. 
Table 2 Mechanical properties of fiber.

\begin{tabular}{llllll}
\hline ID & Fiber & $\begin{array}{l}\text { Length } \\
(\mathrm{mm})\end{array}$ & $\begin{array}{l}\text { Diameter } \\
(\mathrm{mm})\end{array}$ & $\begin{array}{l}\text { Tensile strength } \\
(\mathrm{MPa})\end{array}$ & $\begin{array}{l}\text { Elastic modulus } \\
(\mathrm{GPa})\end{array}$ \\
\hline No. 30 & Aramid & 30 & 0.5 & 3,432 & 73 \\
No. 31 & PP & 30 & 0.7 & 580 & 4.6 \\
No. $32^{\dagger}$ & PVA & 12 & 0.1 & 1,200 & 28 \\
\hline
\end{tabular}

${ }^{\dagger}$ Specimen No. 32 is from the previous study [23].
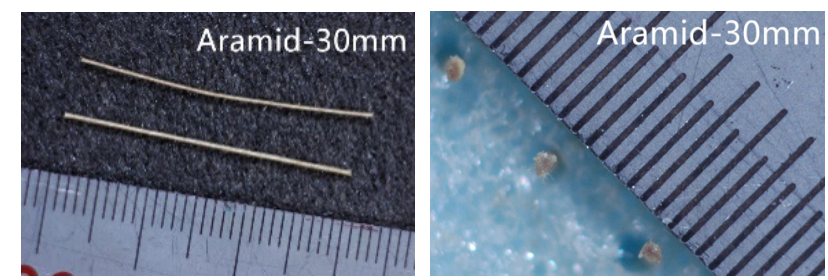

Fig. 1 Aramid fiber and PP fiber used in this study.

to fail by shear in panel zone before flexural yielding to evaluate the shear performance of joint panel. FRCCs were only used in the panel zone. Dimensions of the FRCC beam-column joints are shown in Fig. 2 and Table 3. The column section was $500 \mathrm{~mm} \times 500$ $\mathrm{mm}$ and the beam section was $380 \mathrm{~mm}$ wide and 420 $\mathrm{mm}$ deep. The span of beam and column was 2,700 $\mathrm{mm}$ and $1,560 \mathrm{~mm}$ which is considered as a half scale of real RC structure. High strength rebars were adopted for main reinforcing bars in beam and column to insure the priority of shear failure in panel zone. To grasp the fiber influence on the shear performance of panel zone, no hoop was used in panel zone.

In order to compare FRCC beam-column joints shear performance better, specimens from previous studies [22, 23] are also listed in this study. The authors have reported the experimental results of No. 24 (without fiber) and No. 32 which is the specimen having 1\% PVA fiber in panel zone. All other parameters are same as this research.

\subsection{Loading Method and Measurement}

The reversed cyclic loading is applied to the beams by controlling story drift angles from $R= \pm 1 / 400$ to $\pm 1 / 20 \mathrm{rad}$. Story drift angle was controlled by the actuators attached to the inflection points of beams, which is shown in Fig. 3. Oil jacks were used on the inflection points to support the columns. The
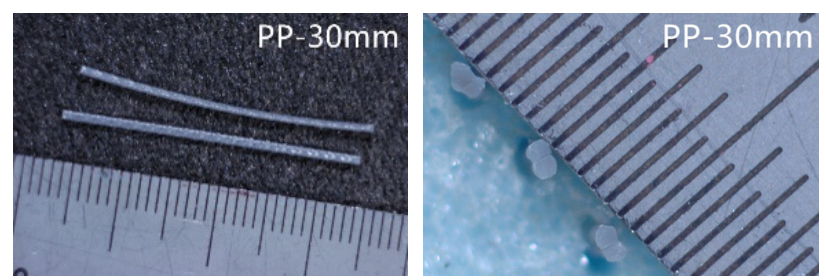

measurements were the applied load on beams, story drift angle, deformations of beam and column. Setups of linear variable displacement transducers (LVDTs) are shown in Figs. 4 and 5.

\section{Test Results}

\subsection{Failure Modes}

Crack patterns of all specimens observed at maximum load are shown in Fig. 6. Except for No. 30, maximum loads of all specimens were observed at the story drift angle $R=1 / 50 \mathrm{rad}$. Since aramid fiber has a higher fiber bridging effect, maximum load of No. 30 was observed at the story drift angle $R=1 / 33 \mathrm{rad}$. For all specimens, shear crack occurred on panel zone first, and then flexural crack and shear crack on beam were observed in this order. Diagonal shear crack on panel zone developed more and more visibly due to crack opening and closing under the increased cyclic load. Large number of diagonal cracks appeared on the surface of panel zone during loading which leads to the shear failure. In comparison with No. 24, the cracks of all specimens with fibers have been inhibited due to the effect of fiber bridging. After maximum load, the cracks of specimens with fibers developed wider and deeper however if compared to No. 24, the change was not obvious. By using fibers into beam-column joint, the damage of panel zone can be improved. 


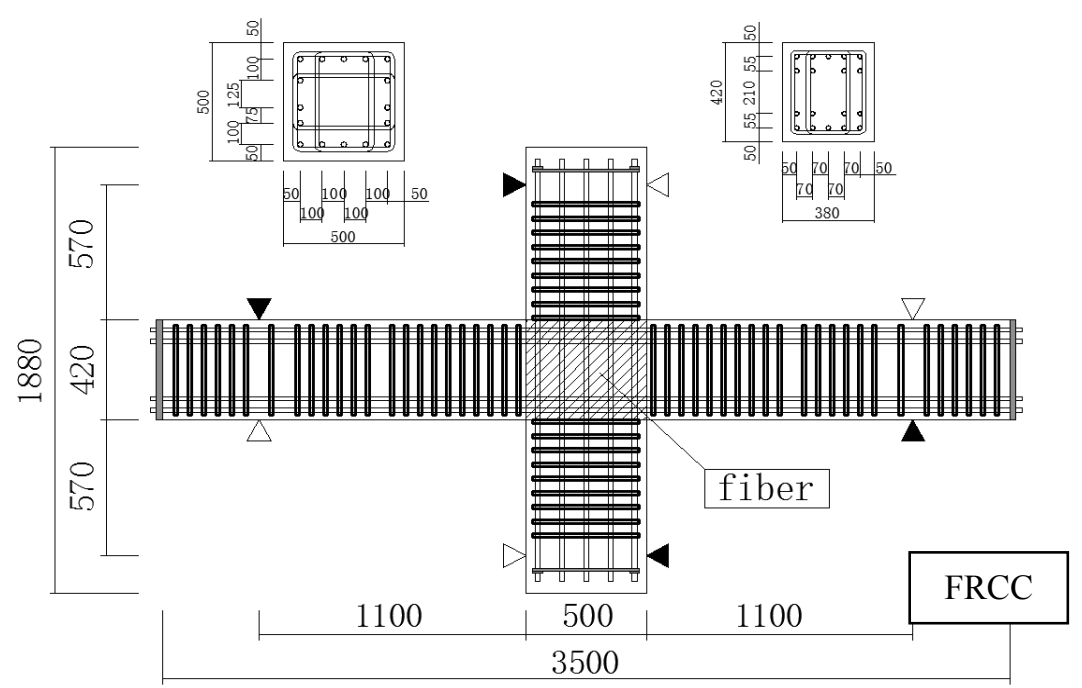

Fig. 2 Specimen dimensions.

Table 3 Specimens list.

\begin{tabular}{|c|c|c|c|c|c|}
\hline \multirow{2}{*}{ ID } & \multirow{2}{*}{$\begin{array}{l}\text { Panel } \\
\text { Parameter }\end{array}$} & \multicolumn{2}{|c|}{ Beam } & \multicolumn{2}{|c|}{ Column } \\
\hline & & Reinforcing bar & Stirrup & Reinforcing bar & Hoop \\
\hline No. $24^{*}$ & Without fiber & \multirow{4}{*}{ 18-D22 (USD685) } & \multirow{4}{*}{ 6-D10@60 (SD785) } & \multirow{4}{*}{ 16-D22 (USD685) } & \multirow{4}{*}{ 6-D10@60 (SD785) } \\
\hline No. 30 & Aramid & & & & \\
\hline No. 31 & PP & & & & \\
\hline No. $32^{\dagger}$ & PVA & & & & \\
\hline
\end{tabular}

Specimen No. 24 is from the previous study [22].

Specimen No. 32 is from the previous study [23].

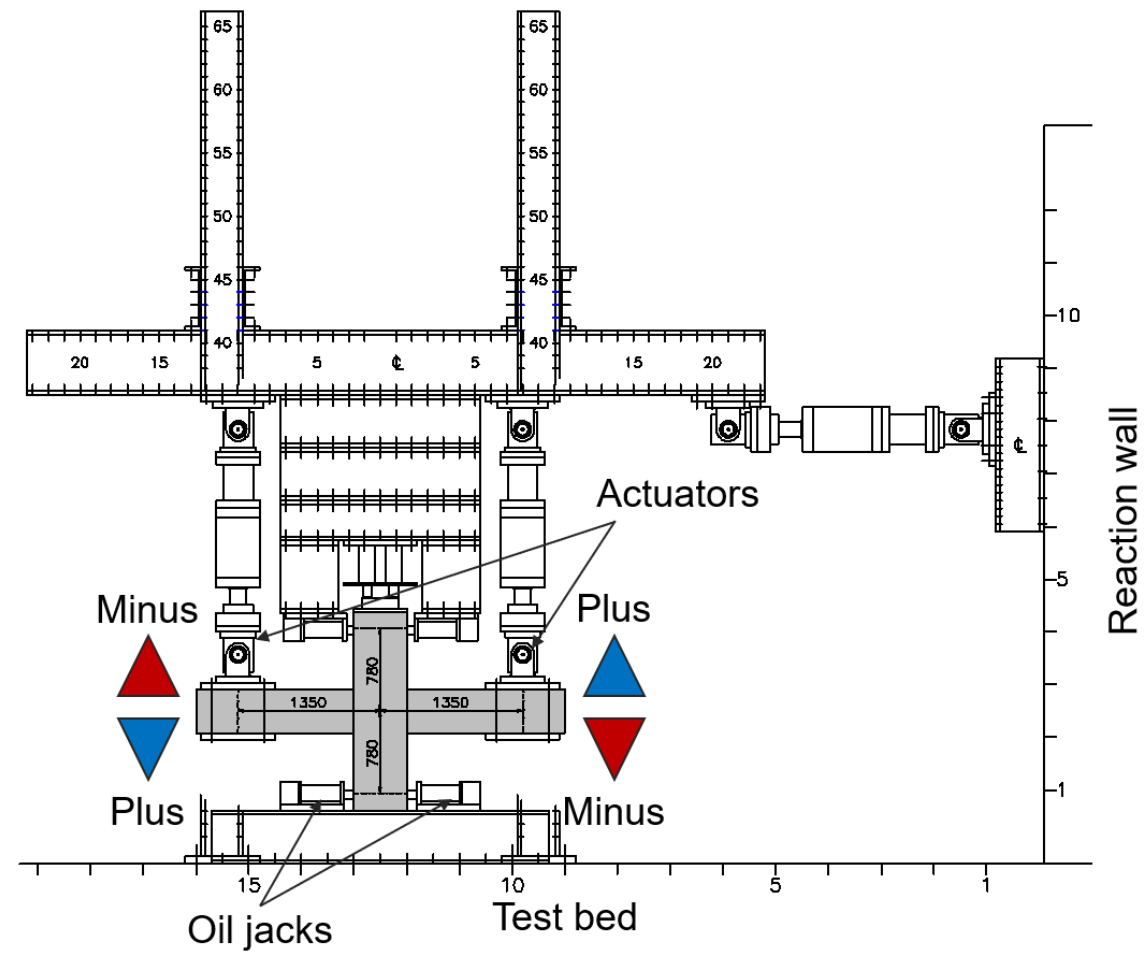

Fig. 3 Loading method. 


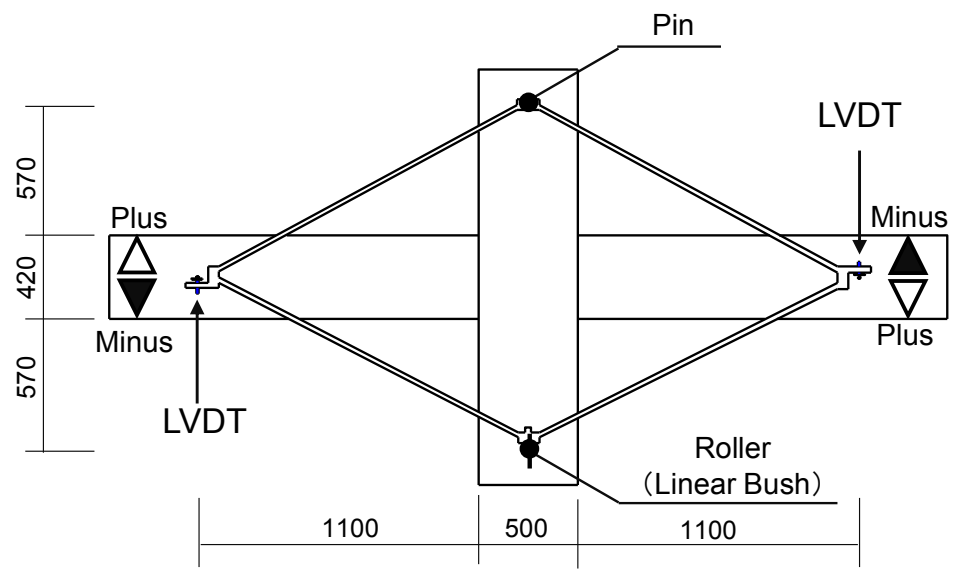

Fig. 4 Measurement of story drift angle.
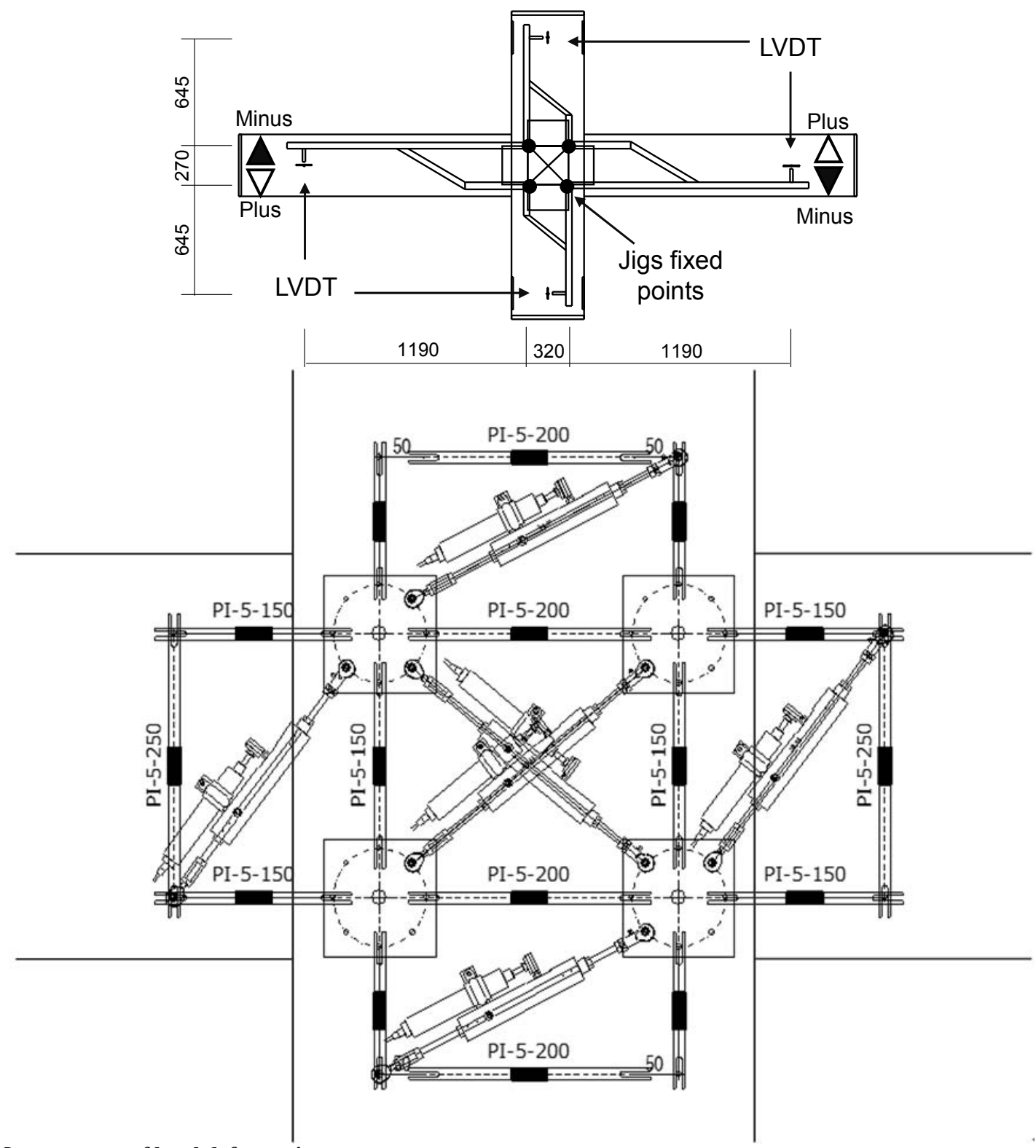

Fig. 5 Measurement of local deformation. 


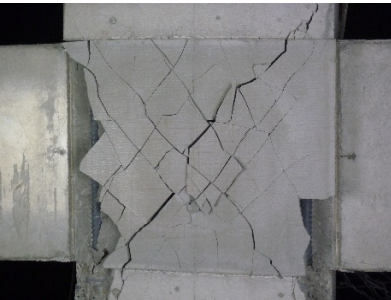

No. 24 (no fiber)

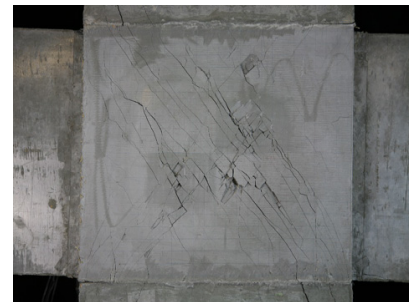

No. 30 (aramid)

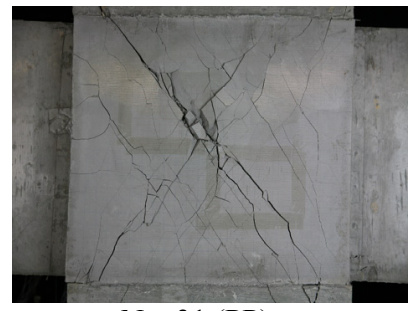

No. 31 (PP)

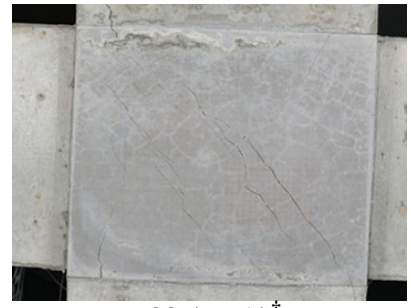

No. 32 (PVA)

Fig. 6 Crack patterns at maximum load.

\subsection{Load-Story Drift Angle Curve}

Fig. 7 shows the relationships of load and story drift angle obtained from the cyclic loading test. The peak loads are listed in Table 4. Specimen No. 30 has the highest value of $544 \mathrm{kN}$, which was mainly attributed by its higher fiber bridging effect. Since all the specimens were designed by failure of panel zone, peak loads of specimens with fibers were increased significantly compared to No. 24 due to the effectiveness of fiber bridging.

\section{Evaluation of Shear Capacity}

\subsection{Outline of Tension Test}

To grasp the tensile characteristics of FRCC, the uniaxial tension test was conducted. Aramid fiber, PP fiber and PVA fiber were used to test the tensile property. The fibers used for the tension test are the same as those used in the beam-column joint experiment. The mixture proportion of mortar matrix has already been presented in Table 1 . The fiber volume fraction is $1 \%$.

The details of the specimen and the loading method are shown in Fig. 8. The total length of the specimen is $510 \mathrm{~mm}$ with carbon fiber sheets attached at both ends to avoid peel-off of the steel plate. Since the increasing external moment caused by setup irregularity and local fracture caused by secondary moment will be an inevitable factor to the experiment, pin-fix ends were applied at the boundaries to minimize possible effects to the results. As shown in Fig. 9, a notch was being made in the middle of the specimen. The sectional area at ligament is $40 \mathrm{~mm} \times$ $40 \mathrm{~mm}$. Tensile load and deformation in the test region were obtained directly from the experiment. The crack width is the average value of two pi-type LVDTs.

\subsection{Results of Tension Test}

All specimens fractured at the ligament. Tensile stress is calculated by tensile load divided by sectional area at the ligament. Fig. 10 shows the example photographs of the fibers across the crack during loading. The relationships of tensile stress versus crack width are shown in Fig. 11. The tensile stress showed a significant drop after first cracking. Due to the fiber bridging effect, the tensile stress increased until to the second peak and then decreased gradually. The average tensile stresses of Aramid, PP and PVA specimens at the second peak are $3.31 \mathrm{MPa}$ (crack width at $0.995 \mathrm{~mm}$ ), $1.61 \mathrm{MPa}$ (crack width at 1.199 $\mathrm{mm}$ ) and $1.80 \mathrm{MPa}$ (crack width at $0.680 \mathrm{~mm}$ ), respectively.

\subsection{Evaluation of Shear Capacity}

By assuming that the shear stress in the panel zone is also carried by fiber bridging effect, shear capacity of beam-column joint is evaluated through the tensile characteristics of FRCC.

It is considered that the strut mechanism in FRCC beam-column joint keeps until to story drift angle of $R$ $=1 / 50 \mathrm{rad}$ due to the bridging effect of fibers which are across the diagonal crack on the surface of panel zone. After that, diagonal cracks start to move to shear sliding direction which leads to the maximum load. At the maximum load, by assuming failure of strut mechanism and disappearance of fiber bridging effect are occurred simultaneously, calculation method for 

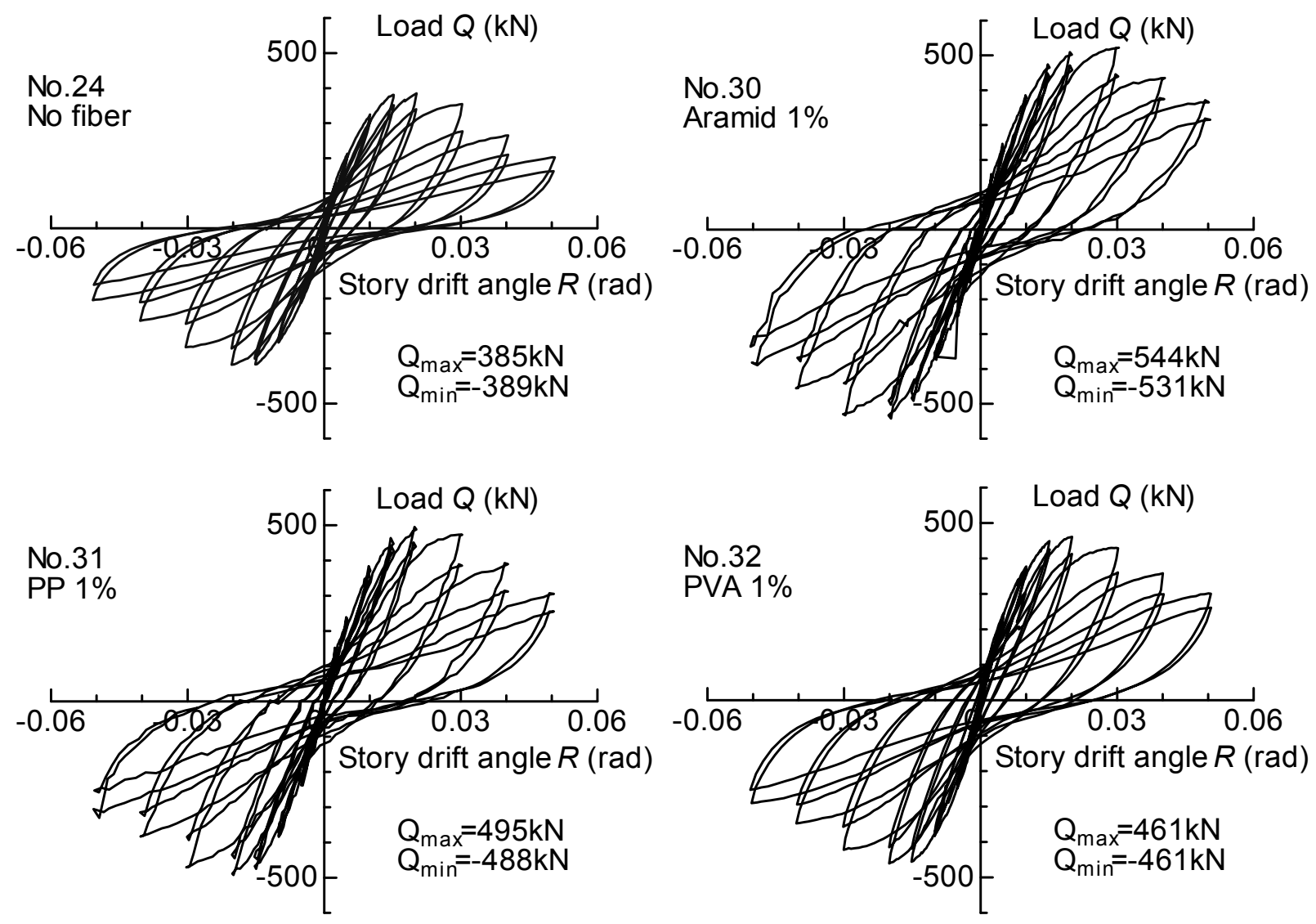

Fig. 7 Load-story drift angle curve.

* Specimen No. 24 is from the previous study [22].

${ }^{\dagger}$ Specimen No. 32 is from the previous study [23].

Table 4 Peak load and story drift angle at peak load.

\begin{tabular}{lll}
\hline & Peak load & Story drift angle \\
\hline No. 24 (no fiber) & $389 \mathrm{kN}$ & $1 / 50 \mathrm{rad}$ \\
No. 30 (aramid) & $544 \mathrm{kN}$ & $1 / 33 \mathrm{rad}$ \\
No. 31 (PP) & $495 \mathrm{kN}$ & $1 / 50 \mathrm{rad}$ \\
No. 32 (PVA) & $461 \mathrm{kN}$ & $1 / 50 \mathrm{rad}$ \\
\hline
\end{tabular}

shear capacity of FRCC beam-column joint in Eq. (1) can be proposed. Eq. (1) is derived as the summation of the Eq. (2) given by "Design Guidelines for Earthquake Resistant Reinforced Concrete Buildings Based on Inelastic Displacement Concept" [26] to shear force carried by FRCC expressed by Eq. (3). As shown in Fig. 12, shear force is derived from tension force carried by fibers. The crack angle $\theta$ is observed directly from the surface of panel zone. The second peak load in uniaxial tension test is adopted for maximum tensile stress in each type of fibers.

Experimental and calculated values of shear capacity are converted to the shear force which is applied to beam. As listed in Table 5, the difference of below $7 \%$ between calculated value and experimental value demonstrates that the calculation method is feasible. By adopting this method, shear capacity of FRCC beam-column joint can be calculated from uniaxial tension test.

$$
\begin{gathered}
V_{j u}=V_{j c}+V_{j f} \\
V_{j c}=\kappa \cdot \varphi \cdot F_{j} \cdot b_{j} \cdot D_{j} \\
V_{j f}=\sigma_{t, \max } \cdot d_{b} \cdot b_{j}
\end{gathered}
$$



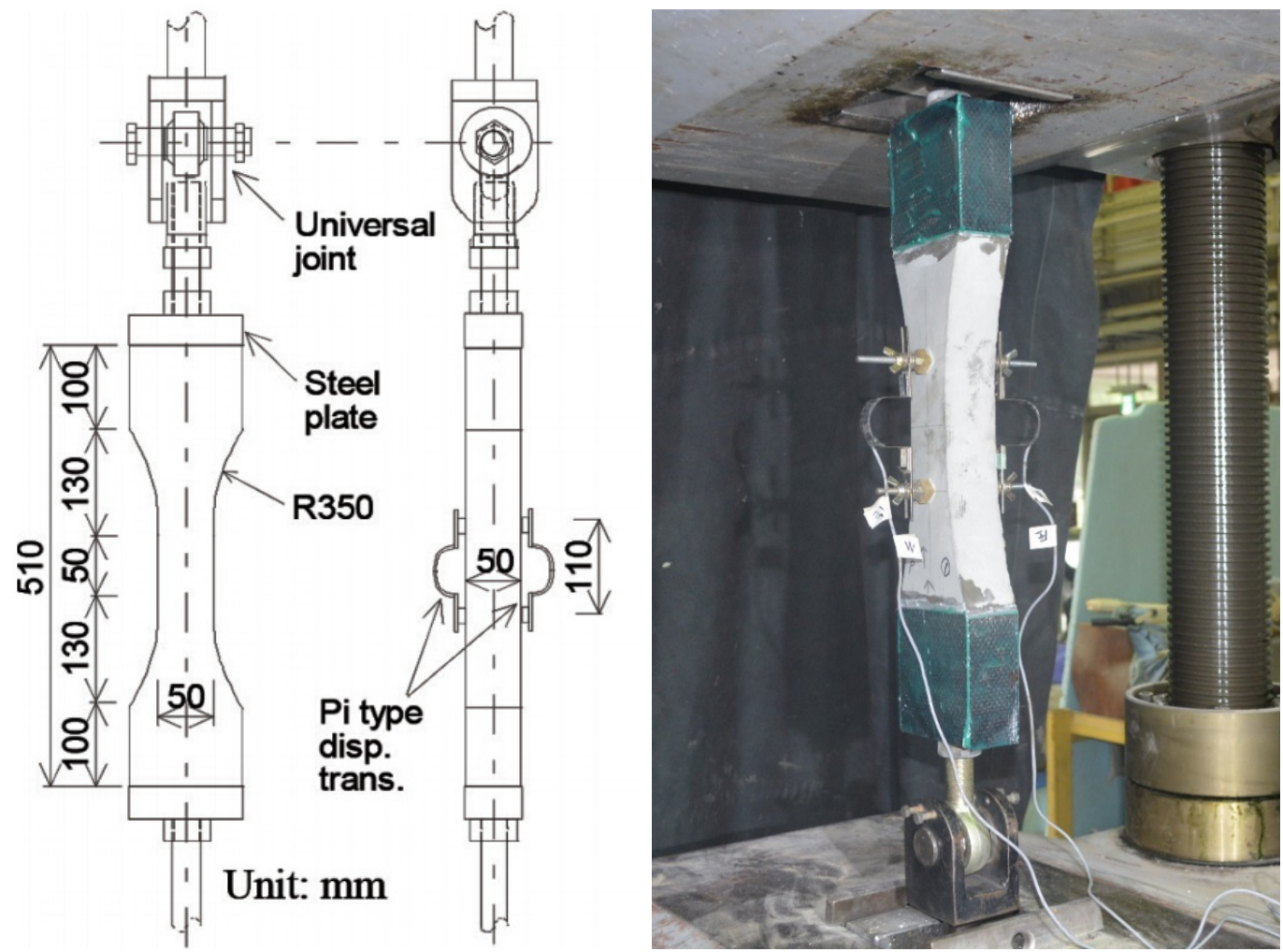

Fig. 8 Tensile test specimen.

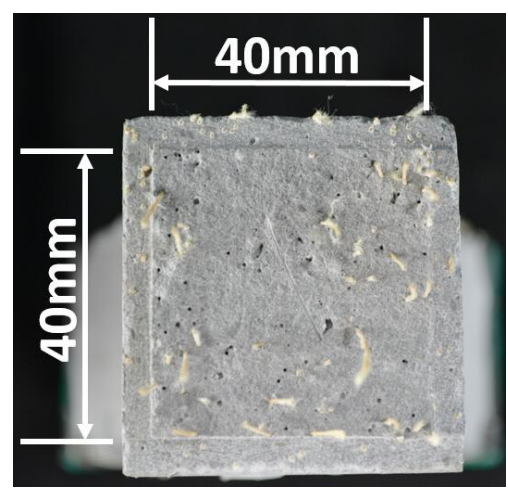

Fig. 9 Cross section of tensile test specimen.
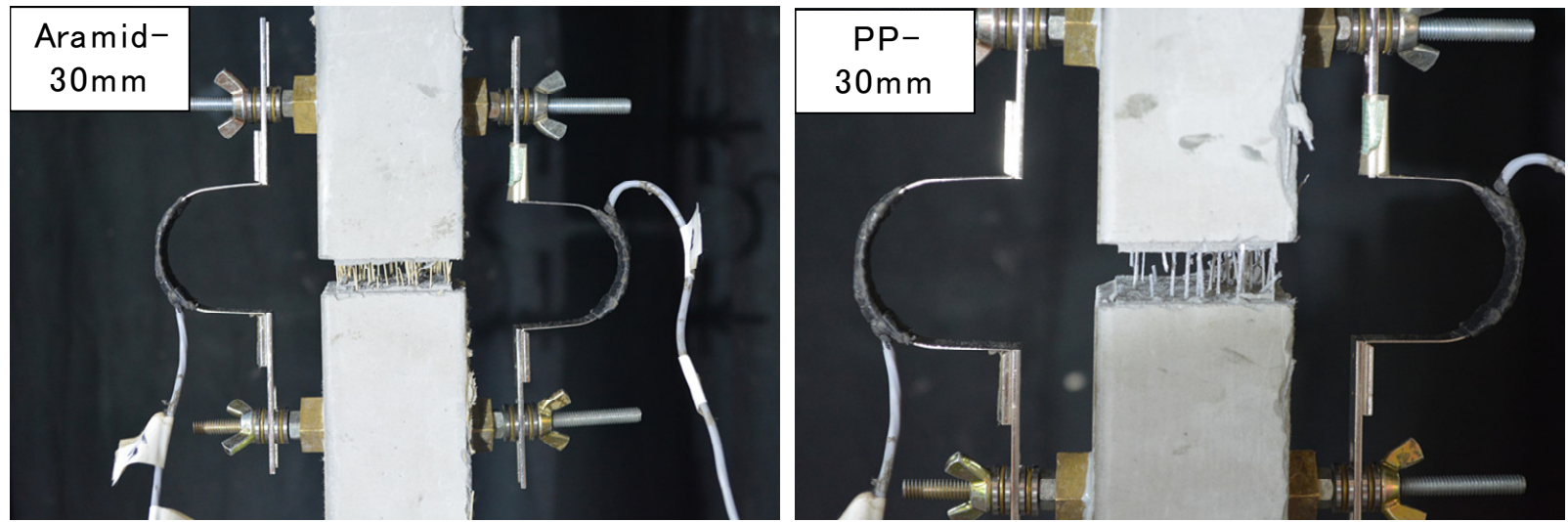

Fig. 10 Fibers across the crack during loading. 

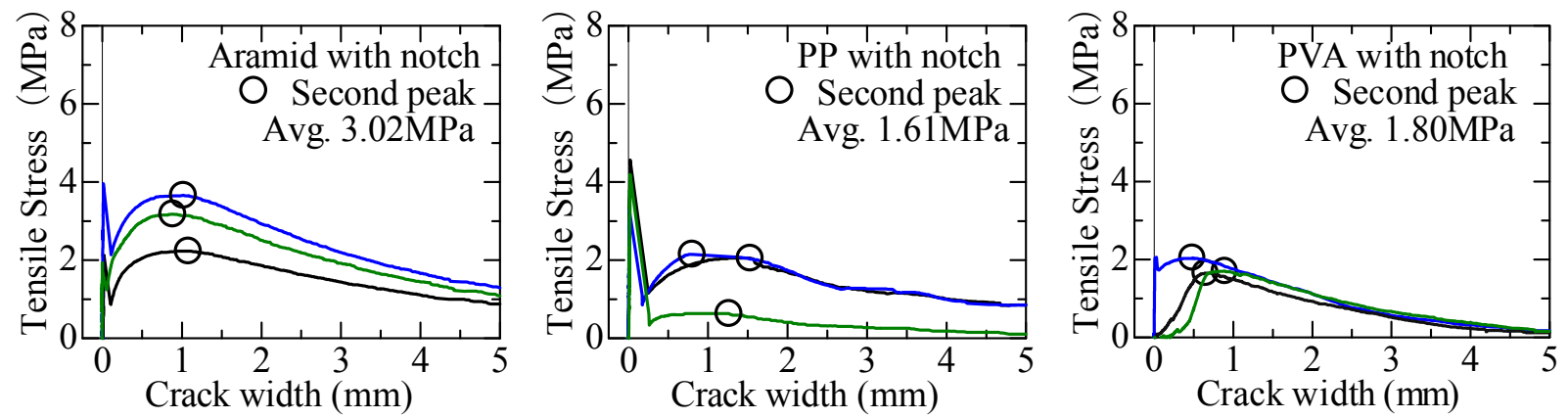

Fig. 11 Tensile stress-crack with curve.

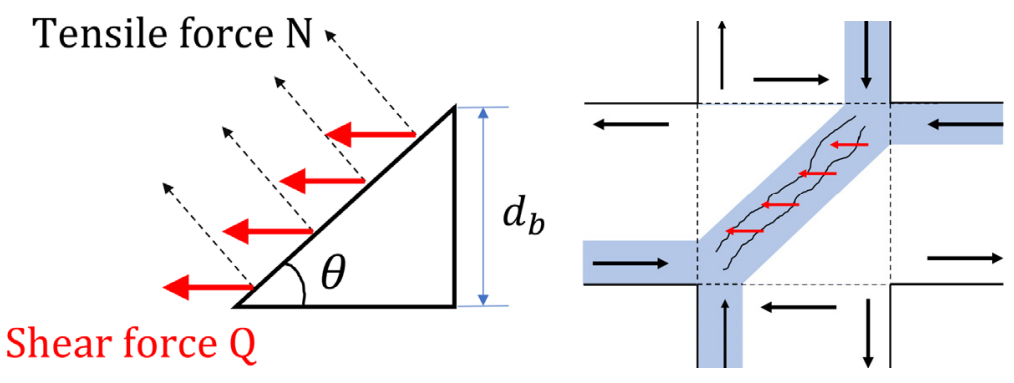

Fig. 12 FRCC beam-column joint under shear.

Table 5 Experimental value and calculated value.

\begin{tabular}{lllll}
\hline & & Aramid & PP & PVA \\
\hline Experimental value $V_{\text {exp }}(\mathrm{kN})$ & & 544 & 495 & 461 \\
& Eq. $(2) V_{j c}(\mathrm{kN})$ & 424 & 426 & 412 \\
Calculated value & Eq. $(3) V_{j f}(\mathrm{kN})$ & 83 & 44 & 49 \\
& Eq. $(1) V_{j u}(\mathrm{kN})$ & 507 & 470 & 461 \\
$V_{\text {exp }} / V_{j u}$ & & 1.07 & 1.05 & 1.00 \\
\hline
\end{tabular}

where, $V_{j u}$ is shear capacity; $V_{j c}$ is shear capacity by AIJ guideline; $V_{j f}$ is shear capacity carried by fiber; $\kappa$ is shape coefficient; $\varphi$ is orthogonal beam coefficient; $F_{j}$ is shear strength of panel zone; $b_{j}$ is effective width; $D_{j}$ is column height; $\sigma_{t, \max }$ is maximum FRCC tensile stress; $d_{b}$ is effective depth of beam.

\section{Conclusions}

To investigate the influence of fiber bridging effect on shear performance of FRCC, beam-column joint test using various polymer fibers was conducted. Due to fiber bridging effect, the shear capacity of specimen with fiber in panel zone increased compared to specimen without fiber. A new proposed calculation method using FRCC tensile stress obtained from uniaxial tension test can predict shear capacity of
FRCC beam-column joint accurately.

\section{Acknowledgments}

The authors acknowledge Mr. Faizal Hanif, former student in University of Tsukuba, for his help to complete the experiments.

\section{References}

[1] Architectural Institute of Japan. 1990. "Design Guidelines for Earthquake Resistant Reinforced Concrete Buildings Based on Ultimate Strength Concept."

[2] Henager, C. H. 1977. "Steel Fibrous Ductile Concrete Joint for Seismic-Resistant Structures." Presented at Symposium on Reinforced Concrete Structures in Seismic Zones, American Concrete Institute, Detroit.

[3] Halvorsen, G. T., and Kesler, C. E. 1979. "Moment-Curvature Relationships for Concrete Beams with Plain and Deformed Steel Fibers." ACI Journal Proceedings 7 (6): 697-706.

[4] Craig, R., Mahadev, S., Patel, C. C., Viteri, M., and 
Kertesz, C. 1984. "Behavior of Joints Using Reinforced Fibrous Concrete." Presented at Fiber Reinforced Concrete-International Symposium, American Concrete Institute, Detroit.

[5] Naaman, A. E., Wight, J. K., and Abdou, H. 1987. "SIFCON Connections for Seismic Resistant Frames." Concrete International: Design \& Construction 9 (11): 34-9.

[6] Olario, I., Ioani, A., and Poienar, N. 1988. "Steel Fiber Reinforced Ductile Joints." Presented at Ninth World Conference on Earthquake Engineering, Tokyo-Kyoto.

[7] Gefken, P. R., and Ramey, M. R. 1989. "Increased Joint Hoop Spacing in Type 2 Seismic Joints Using Fiber Reinforced Concrete." ACI Structural Journal 86 (2): 168-72.

[8] Jiuru, T., Chaobin, H., Kaijian, Y., and Yongcheng, Y. 1992. "Seismic Behavior and Shear Strength of Frames Joint Using Steel-Fiber Reinforced Concrete." Journal of Structural Engineering 118 (2): 341-58.

[9] Katzensteiner, B., Filiatrault, A., Mindess, S., and Banthia, N. 1992. "Use of Steel Fibrous Concrete in Seismic Design." Presented at Fourth RILEM International Symposium on Fibre Reinforced Cement and Concrete, Sheffield.

[10] Durrani, A. J., and Diaz, A. J. 1992. "Seismic Resistance of Fiber-Reinforced Slab-Column Connections." Presented at Tenth World Conference on Earthquake Engineering, Madrid.

[11] Olariu, I., Ioani, A. M., and Poienar, N. 1992. "Seismic Behaviour of Steel Fiber Concrete Beam-Column." Presented at Tenth World Conference on Earthquake Engineering, Madrid.

[12] Filiatrault, A., Pineau, S., and Houde, J. 1995. "Seismic Behavior of Steel-Fiber Reinforced Concrete Interior Beam-Column Joints." ACI Structural Journal 92 (5): 543-52.

[13] Kosa, K., and Naaman, A. E. 1990. "Corrosion of Steel Fiber Reinforced Concrete." ACI Materials Journal 87 (1): 27-37.

[14] Kosa, K., Naaman, A. E., and Hanse, W. 1991. "Durability of Fiber Reinforced Mortar." ACI Materials Journal 88 (3): 310-9.

[15] ACI Committee 544. 1996. 1R-96, State-of-the-Art Report on Fiber Reinforced Concrete. pp. 39-57.

[16] Mu, Y., and Kanakubo, T. 2015. "Bending Test of FRC Notched Beam with Various Polymer Fibers." Summaries of Technical Papers of Annual Meeting Architectural
Institute of Japan (TOHKAI), Material Construction, pp. 511-2.

[17] Kanakubo, T., Miyaguchi, M., and Asano, K. 2016. "Influence of Fiber Orientation on Bridging Performance of Polyvinyl Alcohol Fiber-Reinforced Cementitious Composite." American Concrete Institute Materials Journal 113 (2): 131-41.

[18] Li, V. C., and Obla, K. H. 1994. "Effect of Fiber Length Variation on Tensile Properties of Carbon Fiber Cement Composites." Int'l J. of Composites Engineering 4 (9): 947-64.

[19] Li, V. C., Wu, H. C., Maalej, M., Mishra, D. K., and Hashida, T. 1996. "Tensile Behavior of Cement Based Composites with Random Discontinuous Steel Fibers." J. Amer. Ceramics Soc. 79 (1): 74-8.

[20] Li, V. C., and Wu, H. C. 1992. "Conditions for Pseudo Strain-Hardening in Fiber Reinforced Brittle Matrix Composites.” J. Applied Mechanics Review 45 (8): 390-8.

[21] Li, V. C. 1998. "Engineered Cementitious Composites (ECC)-Tailored Composites through Micromechanical Modeling." In Fiber Reinforced Concrete: Present and the Future, edited by Banthia, N., Bentur, A., and Mufti, A. A. Montreal: Canadian Society for Civil Engineering, pp. 64-97.

[22] Sano, N., Yamada, H., Miyaguchi, M., Yasojima, A., and Kanakubo, T. 2015. "Structural Performance of Beam-Column Joint Using DFRCC." Presented at 11th Canadian Conference on Earthquake Engineering_Facing Seismic Risk, Paper ID 94163.

[23] Mu, Y., Ando, M., Yasojima, A., and Kanakubo, T. 2017. "Influence of Fiber Orientation on Structural Performance of Beam-Column Joints Using PVA FRCC." In RILEM Book Series of Strain-Hardening Cement-Based Composites, SHCC4, pp. 465-72.

[24] Yamada, H., Ando, M., Yasojima, A., and Kanakubo, T. 2016. "Effect of Fiber Types on Shear Performance of Precast Concrete Beam-Column Joints Using DFRCC." Presented at 7th International Conference of Asian Concrete Federation, Vietnam.

[25] Zhang, R., Matsumoto, K., Hirata, T., Ishizeki, Y., and Niwa, J. 2015. “Application of PP-ECC in Beam-Column Joint Connections of Rigid-Framed Railway Bridges to Reduce Transverse Reinforcements." Engineering Structures 86: 146-56.

[26] Architectural Institute of Japan. 1999. "Design Guidelines for Earthquake Resistant Reinforced Concrete Buildings Based on Inelastic Displacement Concept.” 